\title{
The influence of selective vitamin $D$ receptor activator paricalcitol on cardiovascular system and cardiorenal protection
}

This article was published in the following Dove Press journal:

Clinical Interventions in Aging

8 February 2013

Number of times this article has been viewed

\author{
Darko Duplancic' \\ Marijan Cesarik ${ }^{2}$ \\ Nikola Kolja Poljak ${ }^{3}$ \\ Maja Radman ${ }^{4}$ \\ Vedran Kovacic ${ }^{5}$ \\ Josipa Radic ${ }^{5}$ \\ Veljko Rogosic ${ }^{6}$ \\ 'Department of Cardiology, School \\ of Medicine in Split, University \\ Hospital Split, Split, Croatia; \\ ${ }^{2}$ Department for Neurology, \\ County General Hospital Pozega, \\ Pozega, Croatia; ${ }^{3}$ Department of \\ Otorhinolaryngology, ${ }^{4}$ Department \\ of Endocrinology, ${ }^{5}$ Department of \\ Nephrology, ${ }^{6}$ Department \\ of Ophthalmology, School of \\ Medicine in Split, University \\ Hospital Split, Split, Croatia
}

\begin{abstract}
The ubiquitous distribution of vitamin D receptors in the human body is responsible for the pleiotropic effects of vitamin D-receptor activation. We discuss the possible beneficial effects of a selective activator of vitamin D receptor, paricalcitol, on the cardiovascular system in chronic heart failure patients and chronic kidney patients, in light of new trials. Paricalcitol should provide additional clinical benefits over the standard treatment for chronic kidney and heart failure, especially in cases of cardiorenal syndrome.
\end{abstract}

Keywords: vitamin D deficiency, cardiovascular system, albuminuria, inflammation

\section{Introduction}

Vitamin D has important roles in physiological processes, and is primarily involved in calcium and phosphorus homeostasis and bone metabolism. ${ }^{1}$ The active form of vitamin D, or 1 alpha, 25-dihydroxyvitamin D3 (calcitriol), binds to its vitamin D receptor (VDR), a kind of nuclear receptor, and activates the VDR to interact with the retinoid X receptor ( $\mathrm{RXR}$ ) to form the $\mathrm{VDR} / \mathrm{RXR} /$ co-factor complex, which binds to vitamin $\mathrm{D}$ response elements in the promoter region of the target gene.

The ubiquitous VDR distribution in the human body (intestine, kidney, bone, parathyroid gland, immune system, smooth muscle, and myocardium) is responsible for the pleiotropic effects of VDR activation. ${ }^{2}$ Namely, despite its classical action on the musculoskeletal system, vitamin D acts on the cardiovascular system, systemic inflammation, oxidative stress, and immune regulation. ${ }^{3}$ Vitamin D has multiple effects on the immune system, including an anti-inflammatory effect. ${ }^{4}$

Indeed, in many epidemiological studies, vitamin D deficiency has been identified as a risk factor for many diseases not traditionally associated with vitamin D and mineral metabolism, such as cancer, cardiovascular disease, hypertension, and diabetes. ${ }^{5}$ A meta-analysis of observational studies examined the association of $25(\mathrm{OH})$ vitamin $\mathrm{D}$ concentrations with cardiometabolic disorders, and the highest concentrations of $25(\mathrm{OH})$ vitamin $\mathrm{D}$ in serum were associated with a $43 \%$ reduction in cardiometabolic disorders, in comparison with the lower concentrations. The conclusions from the meta-analysis indicated that higher levels of vitamin D among middle-aged and elderly populations were associated with a substantial decrease in cardiovascular disease, type 2 diabetes, and metabolic syndrome. ${ }^{6}$ There was also an association of $25(\mathrm{OH})$ vitamin D concentrations with blood pressure, where each incremental increase in $25(\mathrm{OH})$ vitamin $\mathrm{D}(10 \mathrm{nmol} / \mathrm{L})$ correlated with a decrease in systolic blood pressure, by approximately $0.2 \mathrm{mmHg}{ }^{7}$ Evidence showed an inverse association between vitamin D and visceral adiposity. ${ }^{8}$ 


\section{Mechanisms of vitamin D effects on the cardiovascular system}

The mechanisms for these observed relationships remain unclear. Some suggested mechanisms are the higher atherosclerosis risk factors prevalent in vitamin D deficiency states, such as diabetes and hypertension. Some direct effects of vitamin D on the cardiovascular system could also be involved. Namely, these effects beyond the mineral and bone metabolism could be a consequence of the ubiquitous distribution of VDRs in the cardiovascular system (cardiomyocytes, vascular smooth muscle cells, and endothelial cells). ${ }^{9}$ Stimulation of VDRs with vitamin D has been shown to have a direct impact on the cardiovascular system. Several mechanisms have been proposed in the model of vitamin D's protective effects on the cardiovascular system, including its influence on inflammation, endothelial dysfunction, vascular compliance, inflammation, cell proliferation, and differentiation, as well as its effects relating to parathyroid hormone (PTH) and the renin-angiotensin system. These latter two processes are involved in the initiation and development of endothelial damage and atherosclerosis. ${ }^{10,11}$ There is clear evidence of VDR agonism's impact on the inhibition of cytokines involved in calcification and atheroma formation, ${ }^{12,13}$ on the inhibition of proteins implicated in arterial calcification, ${ }^{14}$ and on preventing thrombosis. ${ }^{15}$

Data from animal models also suggest a direct effect of vitamin D on cardiac and vascular structure. VDR knockout mice show hypertrophic hearts, cardiac fibrosis, and increased cardiac mass. ${ }^{16}$ A protective effect of VDR agonists against cardiac hypertrophy and cardiac fibrosis, possibly through a reduction in cardiac oxidative stress, has also been demonstrated. ${ }^{17}$ Vitamin D therapy also ameliorates oxidative stress injury in some experimental models. ${ }^{18}$ In vitro, vitamin D reduces interleukin (IL)-6 synthesis and nuclear factor- $\kappa \mathrm{B}$ activity, and prevents advanced glycation end-product-induced inhibition of endothelial nitric oxidesynthase production. ${ }^{18}$

\section{Interventional studies on vitamin D replacement therapy and cardiovascular system}

Despite observational and epidemiological data, it is unclear from interventional studies how vitamin D would affect cardiovascular risk. A Women's Health Initiative study ${ }^{19}$ showed no effect of calcium plus low-dose $(10 \mu \mathrm{g} / \mathrm{d})$ vitamin D supplementation on coronary or cerebrovascular risk in 36,282 postmenopausal women followed for 7 years. ${ }^{19}$ Zittermann et al ${ }^{20}$ studied overweight subjects with pronounced vitamin D deficiency $(<30 \mathrm{nmol} / \mathrm{L})$, and observed a significant improvement in risk markers (triglycerides and tumor necrosis factor- $\alpha$ ) after supplementation for 1 year with a daily dose of $83 \mu \mathrm{g}$ vitamin D3. Recently Elamin et $\mathrm{al}^{21}$ conducted a systematic review and meta-analysis to find evidence of vitamin D's effect on cardiovascular-event risk factors. They summarized randomized trials of vitamin D used in an interventional mode, and they could not demonstrate a significant effect of vitamin D on death, stroke, myocardial infarctions, lipid fractions, blood pressure, or blood glucose values. It is also important to mention that they analyzed randomized trials with enrolled participants without severe vitamin D deficiency. In contrast, a previous meta-analysis ${ }^{22}$ of randomized controlled trials on vitamin D supplementation demonstrated that vitamin D supplements were associated with decreases in total mortality rates.

\section{Vitamin D and chronic kidney disease}

Cross-sectional studies have demonstrated an inverse relationship between vitamin D levels and cardiovascular disease in both the general ${ }^{23}$ and chronic kidney populations. ${ }^{24}$ Additionally, there is a higher prevalence of vitamin D deficiency in populations with chronic kidney disease. ${ }^{25}$ There is mineral homeostasis deterioration in renal failure, with disturbances in phosphorus, calcium, PTH, 25-hydroxyvitamin D, 1,25-dihydroxyvitamin D, and fibroblast growth factor-23 concentrations. Kidneys cannot excrete phosphorus, which leads to hyperphosphatemia, and consequently to elevated serum PTH and decreased serum 1,25-dihydroxyvitamin D. ${ }^{26}$ Such abnormalities are recognized as disease called chronic kidney disease-mineral and bone disorder (CKD-MBD), a broad clinical syndrome encompassing mineral, bone, and calcific cardiovascular disturbances (vascular and valvular calcifications). ${ }^{27}$

Lower 1,25(OH)2 vitamin D levels have been also associated with worsened coronary calcification, ${ }^{28}$ suggesting a PTH-independent link between vitamin D and survival.

Teng et al ${ }^{29}$ reported in a historical cohort study among 51,037 chronic hemodialysis patients; the group that received vitamin D had a significant 2-year survival advantage over patients who did not receive it.

\section{Selective vitamin D receptor activation}

Traditionally, because of the kidney's lack of 1-alfa hydroxylation, in chronic kidney disease patients, 1,25dihydroxyergocalciferol (calcitriol) is used for treatment 
of secondary hyperparathyroidism. ${ }^{30}$ Secondary hyperparathyroidism is the main clinical feature of CKD-MBD, characterized by abnormally elevated serum concentrations of $\mathrm{PTH}$, and abnormalities in serum calcium, phosphorous, and vitamin D concentrations. It can lead to many clinical complications, such as bone fractures and vascular calcifications. Vascular calcifications and consequently increased arterial stiffness could produce higher pulse pressure and lead to left-ventricular hypertrophy, ${ }^{31}$ arrhythmias, or finally to death. Indeed, arterial calcifications are correlated with cardiovascular mortality, left-ventricular hypertrophy, and the presence of coronary artery disease. ${ }^{32}$ Atherosclerotic cardiovascular disease is the most common cause of mortality in the dialysis population. ${ }^{33}$ The mortality rate from cardiovascular disease in patients with end-stage renal disease varies between $40 \%$ and $50 \%{ }^{34,35}$

Vitamin D is often administered to chronic kidney patients to mitigate the detrimental effects on bone health and mineral metabolism, although this treatment may be limited by elevations in serum calcium and phosphorus. The main action of vitamin D used for CKD-MBD is based on the suppression of high PTH production in the chiefcells of parathyroid glands and on the control of secondary hyperparathyroidism. Vitamin D can correct parathyroid hormone levels and prevent bone disease. Synthetic 1,25dihydroxyvitamin D (calcitriol) binds more selectively to the VDR than does vitamin D or 25-hydroxyvitamin D. In chronic kidney patients, calcitriol effectively suppresses PTH production and improves bone histology. ${ }^{36}$ The therapeutic use of calcitriol mainly aims to raise the intestinal absorption of calcium, to protect bone against osteomalacia, and to control parathyroid function.

As vitamin D can promote the increase of serum calcium and phosphorus levels, there are concerns about the possible side effects of vitamin D preparations. Hyperphosphatemia and hypercalcemia have been shown to promote calcification of the vasculature, myocardium, and cardiac valves. Undesirable effects of vitamin D, such as an increase in calcium and phosphate, may favor the development of vascular calcifications. Vascular calcification and calcification of arteriolar media are the main pathophysiological features of cardiovascular disease in the kidney disease population. Vascular calcification is currently accepted as an actively regulated process similar to bone formation, with changes in the phenotype of vascular smooth muscle cells resulting in osteoblast-like cells that produce calcification-regulating proteins..$^{37}$ Bas et $a l^{38}$ demonstrated that high doses of calcitriol given to uremic rats produced aortic calcifications; these changes were partially reversible several weeks after discontinuation of calcitriol administration. This process of vascular calcification was not correlated with vitamin D alone. Indeed, in animals, vitamin D excess would not induce calcification if serum phosphate was controlled, and it seems that phosphorus has a pivotal role in the promotion of vascular calcification in a vitamin D-administration environment. ${ }^{39}$ Newer vitamin D analogs have been suggested to be less calcemic than is calcitriol. ${ }^{40}$

Several new vitamin D analogs have been developed for treatment of secondary hyperparathyroidism, with a reduced risk of hypercalcemia and hyperphosphatemia. The third generation of vitamin D analogs comprises a group of 1- and 25-hydroxylated vitamin D compounds with structure modifications (19-nor-1,25-dihydroxyvitamin D2 or paricalcitol), which have fewer calcemic and less phosphatemic effects when compared to calcitriol. ${ }^{41}$ Vitamin D analogs have different effects on nuclear VDRs than does calcitriol, through different response elements in various target genes. Experimental work shows that for similar serum concentrations of calcium and phosphate, paricalcitol produces less vascular calcification than does calcitriol, suggesting differential effects at the cellular level. ${ }^{42}$ Such new vitamin D analogs, because of the unique properties of nuclear VDRs, are named selective vitamin $D$ receptor activation agents. The term "selective" means that the molecule acts mostly on the parathyroid gland, more so than on intestine and bone, resulting in lower serum calcium and phosphorus blood concentrations. Such selective VDR-activation agents are reported to have anti-inflammatory and antithrombotic effects, and could inhibit vascular smooth muscle cell proliferation, the reninangiotensin system, and vascular calcification and stiffening, and could regress left-ventricular hypertrophy. ${ }^{43}$

\section{Paricalcitol and cardiorenal protection}

Paricalcitol is the third generation of vitamin D analog, and is a selective activator of VDR used for the treatment of secondary hyperparathyroidism. ${ }^{44}$ Compared with calcitriol, paricalcitol reduces PTH, with significantly fewer episodes of hypercalcemia in hemodialysis patients..$^{45}$ Reduced episodes of hypercalcemia among patients who received paricalcitol compared to calcitriol could be explained due to reduced stimulation of intestinal calcium transport proteins. ${ }^{46}$ Calcitriol in uremic rats fed with a high-phosphorus diet enhances intestinal calcium absorption, because calcitriol promotes calbindin expression, whereas paricalcitol does not. ${ }^{47}$ There are also data on lower absorption rates of 
calcium and phosphorus among patients receiving paricalcitol, compared with calcitriol. ${ }^{48,49}$

The vascular calcification process in chronic kidney disease is also directly influenced by paricalcitol. Activation of VDR has been shown to decrease the process of vascular calcification, the main cardiovascular feature of chronic kidney disease, through suppression of calcification inducers such as type I collagen, bone sialoprotein, interleukin-1 $\beta$, and tumor necrosis factor-alpha, or through activation of calcification supressors: matrix Gla protein, osteopontin, and osteocalcin. ${ }^{50} \mathrm{Li}$ et $\mathrm{al}^{51}$ demonstrated direct protection from vascular calcifications with paricalcitol, and found that paricalcitol could influence proteins involved in the smooth muscle cell calcification process, including bone morphogenetic protein-2 (BMP2), tumor necrosis factor-alpha, and osteopontin. Osteopontin could directly regulate vascular calcification and was found to contribute to the inhibitory actions of paricalcitol in the calcification of smooth muscle cell. The direct influence of paricalcitol on VDRs located on vascular smooth muscle cells could be explained by different effects of paricalcitol on target genes involved in the pathogenesis of vascular calcifications, independently of previously suggested mechanisms, such as modulation of the inflammatory response or different hyperphosphathemic and hypercalcemic effects.

Paricalcitol seems to have several mechanisms of action, because activation of the VDR intervenes in pathways associated with cardiovascular disease (suppression of renin transcription, antiproliferative effects, antifibrotic effects) ${ }^{52}$ Data support a potential role of selective VDR activation in preventing the pathogenesis of atherosclerosis in chronic kidney disease. Activation of VDR also impacts the cardiovascular system by decreasing the activation of the renin-angiotensinaldosterone system. There is evidence of an inverse relationship between vitamin D levels and plasma renin activity. ${ }^{53}$ Paricalcitol was found to decrease angiotensinogen, renin, renin receptor, and vascular endothelial growth factor mRNA levels in a rat model of chronic renal failure. ${ }^{54}$

In a rat model of gentamicin-induced renal injury, paricalcitol prevented upregulated inflammatory cytokines (tumor necrosis factor-alpha, interleukin-1beta, interferongamma), nuclear factor-kappaB and phosphorylated ERK1/2 expression, and adhesion molecules (monocyte chemoattractant protein-1, ICAM-1, VCAM-1), and they reversed the transforming growth factor (TGF)-beta1-induced epithelial-to-mesenchymal transition process and extracellular matrix accumulation. ${ }^{55}$ Paricalcitol has significant immunomodulatory activity via VDR agonism, based on its inhibition of dendritic cells, which are important in the pathogenesis of atherosclerosis. ${ }^{56}$ The antioxidative properties of paricalcitol were demonstrated, in an animal model of contrast-induced nephropathy, by lower levels of serum malondialdehyde and kidney thiobarbituric acid-reacting substances in the paricalcitol group. ${ }^{57}$ Antifibrotic effects of paricalcitol were reported by Meems et $\mathrm{al}^{58}$ in an animal model: paricalcitol reduced myocardial fibrosis and preserved diastolic left-ventricular function due to pressure overload associated with reduced fibrosis. A similar study revealed the protective effect of enalapril and paricalcitol, alone or in combination, on cardiac oxidative stress in uremic rats. ${ }^{59}$ Paricalcitol prevented cisplatin-induced kidney injury by suppressing fibrotic, apoptotic, and proliferative factors in an animal model; paricalcitol suppressed expression of TGF- $\beta 1$, Smad signaling, mitogen-activated protein kinase signaling, p53-induced apoptosis, and p27(kip1). ${ }^{60}$ Additionally, combination of enalapril and paricalcitol reduced glomerulosclerosis, proteinuria, and inflammation - when measured as monocyte chemoattractant protein-1 (MCP-1) in uremic rats - via suppression of TGF $\beta$ - 1 and Smad2.${ }^{61}$ Paricalcitol combined with enalapril had an additional protective effect on aortic inflammatory and oxidative injury biochemical markers in atherosclerotic mice. ${ }^{62}$ Kong et $\mathrm{al}^{63}$ tested, in an interesting study of spontaneously hypertensive rats, the effects of losartan, paricalcitol, doxercalciferol, a combination of losartan and paricalcitol, or a combination of losartan and doxercalciferol, on the development of left-ventricular hypertrophy. Echocardiograpy demonstrated a $65 \%$ to $80 \%$ reduction in left-ventricular wall thickness with losartan, paricalcitol, or doxercalciferol monotherapy, and almost complete prevention of left-ventricular hypertrophy with the combination therapies. Renal and cardiac renin expression was markedly increased in losartan-treated animals, but nearly normalized with combination therapy. These data demonstrate that vitamin $\mathrm{D}$ analogs have potent antihypertrophic activity, partly by suppressing renin in the kidney and heart. Paricalcitol also suppresses the progression of left-ventricular hypertrophy, myocardial and perivascular fibrosis, and myocardial arterial vessel thickness in uremic rats by upregulating the VDRs. ${ }^{64}$ Fraga et a ${ }^{65}$ demonstrated that paricalcitol prevented decrease in myocardial VDR expression. As VDRs are expressed in cardiac myocytes, the effect of paricalcitol could have a clinical impact on uremic cardiomyopathy, a common complication in patients with chronic kidney disease, characterized by cardiac fibrosis, cardiac hypertrophy, and diastolic dysfunction. Wu-Wong et $\mathrm{al}^{66}$ demonstrated that VDR activation with 
paricalcitol improved endothelial function, measured as endothelial-dependent vasorelaxation in a chronic kidney disease rat model, independently of the parathyroid hormone suppression effect.

As vascular calcification is associated with cardiovascular disease in chronic kidney patients, there is concern over vitamin D's possible effects on calcium, phosphorus, and consequently, on vascular calcifications. Mizobuchi et $\mathrm{al}^{67}$ demonstrated that paricalcitol, in contrast to calcitriol and doxercalciferol, had no effect on the serum calciumphosphate product or aortic calcium content in uremic rats. A higher dose of paricalcitol still had no effect, but lowering doxercalciferol levels did not increase the calcium-phosphate product; rather, it increased the aortic calcium content, suggesting independent paricalcitol-mediated mechanisms for protection from vascular calcification. Cardús et a ${ }^{68}$ tested the effects of calcitriol and paricalcitol on vascular smooth muscle-cell calcification in an animal end-stage renal disease model, and concluded that calcitriol, but not paricalcitol, increased calcification of vascular smooth muscle cells, independently of the levels of calcium and phosphate.

Besides these experimental data, observational studies in hemodialysis patients reported improved cardiovascular and all-cause survival among those receiving selective VDR activation therapies. The selective VDR activation agent paricalcitol has been associated with greater survival than nonselective VDR activators such as calcitriol. Indeed, one observational study demonstrated a better 36-month survival rate of patients on dialysis treated with paricalcitol, compared with calcitriol. ${ }^{69}$ A possible explanation for the differential effects of paricalcitol and calcitriol on survival is mineral metabolism. Calcitriol could have a larger gastrointestinal absorption rate of calcium and phosphorus than does paricalcitol, so vascular calcification and death from cardiovascular causes could be increased in patients receiving calcitriol. Another observational study among 7731 hemodialysis patients also demonstrated better survival in patients on doxercalciferol and paricalcitol, versus calcitriol. ${ }^{70} \mathrm{~A}$ recent observational study ${ }^{71}$ also revealed that paricalcitol was associated with improved 2-year survival in dialysis patients, even with low serum iPTH levels, so the differential effects of paricalcitol and calcitriol on survival are not correlated only with different effects on mineral metabolism or on PTH; they could be related to additional pleiotropic effects of paricalcitol.

\section{Paricalcitol in clinical trials}

Despite some animal models and small studies of human participants, there are only a few human randomized trials that might clarify the influence of selective VDR activation on the cardiovascular system in chronic kidney and/or chronic heart failure patients. Paricalcitol appears to block the renin-angiotensin-aldosterone system, and could have an effect on proteinuria via the suppression $\beta$-catenin-mediated gene transcription and prevention of podocyte dysfunction. ${ }^{72}$ In a small study on diabetic and nondiabetic nephropathy, paricalcitol reduced proteinuria mostly in patients with diabetic nephropathy. ${ }^{73}$ Another study demonstrated, in 220 chronic kidney patients, the reduction in proteinuria through paricalcitol treatment, independent of any concomitant use of agents to block the renin-angiotensin-aldosterone system. ${ }^{74}$

In the VITamin D and OmegA-3 TriaL (VITAL), ${ }^{75}$ a randomized clinical trial, paricalcitol demonstrated the additional effect of lowering albuminuria in patients with diabetic nephropathy. The study enrolled 281 patients being treated with angiotensin-converting enzyme inhibitors or angiotensin receptor blockers. The antiproteinuric effect was stronger when sodium dietary intake was higher. This renal protective effect seemed to be associated with renin transcription suppression, together with an antifibrotic and antiproliferative effect, and possibly with lower blood pressure in the paricalcitol group. These antiproteinuric effects were correlated with paricalcitol, and returned to baseline values upon paricalcitol withdrawal. As albuminuria is a surrogate end point, further clinical data are needed to establish the potential effects of selective VDR activation on hard end-point markers in chronic renal disease.

Despite plenty of observational data on the association of vitamin D with decreased cardiovascular-related morbidity and mortality, Paricalcitol Capsule Benefits in Renal FailureInduced Cardiac Morbidity (PRIMO), ${ }^{76}$ a randomized controlled trial on a group of 227 patients with chronic kidney disease with mild-to-moderate left-ventricular hypertrophy and preserved left-ventricular ejection fraction, could not demonstrate the influence of 48 weeks of paricalcitol therapy on the left-ventricular mass index or on Doppler measures of diastolic dysfunction.

\section{Conclusion}

The anti-inflammatory and anti-oxidative properties of paricalcitol could influence clinical end points and result in improvement of cardiovascular and inflammatory parameters in chronic heart failure patients, chronic kidney patients, and uremic patients on renal replacement therapy. The effect of the selective activation of VDR on the cardiovascular system, 
inflammation, and oxidative stress is not fully understood. Although one study ${ }^{76}$ examined the impact of paricalcitol on heart function, participants in this study were chronic renal patients, and were not receiving renal replacement therapy, despite uremic cardimyopathy being the most prevalent among dialysed patients.

Studies in future should emphasize the influence of oral or intravascular treatment with paricalcitol on cardiac function, endothelial function (flow-mediated dilatation), vascular morphology (plaque formation and intima media thickness), and markers of inflammation and oxidative stress in chronic kidney and heart failure patients. Paricalcitol should provide additional cardioprotective and renoprotective effects, with significant clinical benefits for chronic kidney and heart failure, especially in concomitant kidney and heart dysfunction, which is a common clinical presentation recognized today as cardiorenal syndrome. Paricalcitol could produce notable and measurable clinical benefits, superior to those of standard cardiorenal syndrome treatments.

\section{Disclosure}

The authors report no conflicts of interest in this work.

\section{References}

1. Webb RA. Who, what, where and when - influences on cutaneous vitamin D synthesis. Prog Biophys Mol Biol. 2006;92:17-25.

2. Dusso AS, Brown AJ, Slatopolsky E. Vitamin D. Am J Physiol Renal Physiol. 2005;289:8-28.

3. Grant WB, Holick MF. Benefits and requirements of vitamin D for optimal health: A review. Altern Med Rev. 2005;10:94-111.

4. Lappe JM, Travers-Gustafson D, Davies KM, et al. Vitamin D and calcium supplementation reduces cancer risk: results of a randomized trial. Am J Clin Nutr. 2007;85:1586-1591.

5. Gouni-Berthold I, Krone W, Berthold HK. Vitamin D and cardiovascular disease. Curr Vasc Pharmacol. 2009;7:414-422.

6. Parker J, Hashmi O, Dutton D, et al. Levels of vitamin D and cardiometabolic disorders: systematic review and meta-analysis. Maturitas. 2010;65:225-236.

7. Scragg R, Sowers M, Bell C. Serum 25-hydroxyvitamin D, ethnicity, and blood pressure in the Third National Health and Nutrition Examination Survey. Am J Hypertens. 2007;20:713-719.

8. Freedman BI, Wagenknecht LE, Hairston KG, et al. Vitamin D, adiposity, and calcified atherosclerotic plaque in African-Americans. J Clin Endocrinol Metab. 2010;95:1076-1083.

9. DeLuca HF. Overview of general physiologic features and functions of vitamin D. Am J Clin Nutr. 2004;80(Suppl 6):S1689-S1696.

10. Mitsuhashi T, Morris RC Jr, Ives HE. 1,25-dihydroxyvitamin D3 modulates growth of vascular smooth muscle cells. J Clin Invest. 1991;87:1889-1895.

11. Michos ED, Melamed ML. Vitamin D and cardiovascular disease risk. Curr Opin Clin Nutr Metab Care. 2008;11:7-12.

12. Panichi V, De Pietro S, Andreini B, et al. Calcitriol modulates in vivo and in vitro cytokine production: a role for intracellular calcium. Kidney Int. 1998;54:1463-1469.

13. Bellows CG, Reimers SM, Heersche JN. Expression of mRNAs for type-I collagen, bone sialoprotein, osteocalcin, and osteopontin at different stages of osteoblastic differentiation and their regulation by 1,25 dihydroxyvitamin D3. Cell Tissue Res. 1999;297:249-259.
14. Drissi H, Pouliot A, Koolloos C, et al. 1,25-(OH)2-vitamin D3 suppresses the bone-related Runx2/Cbfa1 gene promoter. Exp Cell Res. 2002;274:323-333.

15. Aihara K, Azuma H, Akaike M, et al. Disruption of nuclear vitamin D receptor gene causes enhanced thrombogenicity in mice. $J$ Biol Chem. 2004;279:35798-35802.

16. Simpson RU, Hershey SH, Nibbelink KA. Characterization of heart size and blood pressure in the vitamin D receptor knockout mouse. J Steroid Biochem Mol Biol. 2007;103:521-524.

17. Meems LM, van der Harst P, van Gilst WH, de Boer RA. Vitamin D biology in heart failure: molecular mechanisms and systematic review. Curr Drug Targets. 2011;12:29-41.

18. Talmor Y, Golan E, Benchetrit $\mathrm{S}$, et al. Calcitriol blunts the deleterious impact of advanced glycation end products on endothelial cells. Am J Physiol Renal Physiol. 2008;294:1059-1064.

19. Hsia J, Heiss G, Ren H, et al. Calcium/vitamin D supplementation and cardiovascular events. Circulation. 2007;115:846-854.

20. Zittermann A, Frisch S, Berthold HK, et al. Vitamin D supplementation enhances the beneficial effects of weight loss on cardiovascular disease risk markers. Am J Clin Nutr. 2009;89:1321-1327.

21. Elamin MB, Abu Elnour NO, Elamin KB, et al. Vitamin D and cardiovascular outcomes: a systematic review and meta-analysis. $J$ Clin Endocrinol Metab. 2011;96:1931-1942.

22. Autier P, Gandini S. Vitamin D supplementation and total mortality: a meta-analysis of randomized controlled trials. Arch Intern Med. 2007;167(16):1730-1737.

23. Dobnig H, Pilz S, Scharnagl H, Renner W, et al. Independent association of low serum 25-hydroxyvitamin $\mathrm{d}$ and 1,25-dihydroxyvitamin $\mathrm{d}$ levels with all-cause and cardiovascular mortality. Arch Intern Med. 2008;168:1340-1349.

24. Inaguma D, Nagaya H, Hara K, et al. Relationship between serum 1,25-dihydroxyvitamin D and mortality in patients with pre-dialysis chronic kidney disease. Clin Exp Nephrol. 2008;12:126-131.

25. Baker LR, Abrams L, Roe CJ, et al. 1,25(OH)2D3 administration in moderate renal failure: a prospective double-blind trial. Kidney Int. 1989;35:661-669.

26. Moe SM, Drüeke TB, Block GA, et al. KDIGO clinical practice guidelines for the diagnosis, evaluation, prevention, and treatment of chronic kidney disease-mineral and bone disorder (CKD-MBD). Kidney Int Suppl. 2009;113:S1-S130.

27. Moe S, Drüeke T, Cunningham J, et al. Definition, evaluation, and classification of renal osteodystrophy: a position statement from Kidney Disease: Improving Global Outcomes (KDIGO). Kidney Int. 2006; 69:1945-1953.

28. Watson KE, Abrolat ML, Malone LL, et al. Active serum vitamin D levels are inversely correlated with coronary calcification. Circulation. 1997;96:1755-1760.

29. Teng M, Wolf M, Ofsthun MN, et al. Activated injectable vitamin D and hemodialysis survival: a historical cohort study. J Am Soc Nephrol. 2005;16:1115-1125.

30. Bianchi ML, Colantonio G, Campanini F, et al. Calcitriol and calcium carbonate therapy in early chronic renal failure. Nephrol Dial Transplant. 1994;9:1595-1599.

31. Yildiz A, Memisoglu E, Oflaz H, et al. Atherosclerosis and vascular calcification are independent predictors of left ventricular hypertrophy in chronic haemodialysis patients. Nephrol Dial Transplant. 2005;20:760-767.

32. London GM. Cardiovascular calcifications in uremic patients: clinical impact on cardiovascular function. J Am Soc Nephrol. 2003;9 Suppl 4: S305-S309.

33. Foley RN, Parfrey PS, Sarnak MJ. Clinical epidemiology of cardiovascular disease in chronic renal disease. Am J Kidney Dis. 1998; 32:S112-S119.

34. [No authors listed]. VI. Causes of death in ESRD. Am J Kidney Dis. 1999;34(2 Suppl 1):S87-S94.

35. [No authors listed]. V. Patient mortality and survival in ESRD. Am J Kidney Dis. 1999;34:(2 Suppl 1):S74-S86. 
36. Goodman WG, Coburn JW. The use of 1,25-dihydroxyvitamin D3 in early renal failure. Аnnu Rev Med. 1992;43:227-237.

37. Demer LL, Tintut Y. Vascular calcification: pathobiology of multifaceted disease. Circulation. 2008;117:2938-2948.

38. Bas A, Lopez I, Perez J, Rodriguez M, Aguilera-Tejero E. Reversibility of calcitriol-induced medial artery calcification in rats with intact renal function. J Bone Miner Res. 2006;21:484-490.

39. Stubbs JR, Liu S, Tang W, et al. Role of hyperphosphatemia and 1,25dihydroxyvitamin $\mathrm{D}$ in vascular calcification and mortality in fibroblastic growth factor 23 null mice. J Am Soc Nephrol. 2007;18:2116-2124.

40. Cozzolino M, Brancaccio D, Gallieni M, Slatopolsky E. Pathogenesis of vascular calcification in chronic kidney disease. Kidney Int. 2005;68:429-436.

41. Brown AJ, Finch J, Takahashi F, Slatopolsky E. Calcemic activity of 19-Nor-1,25(OH)(2) $\mathrm{D}(2)$ decreases with duration of treatment. $J \mathrm{Am}$ Soc Nephrol. 2000;11:2088-2094.

42. Mizobuchi M, Ogata H, Koiwa F, Kinugasa E, Akizawa T. Vitamin D and vascular calcification in chronic kidney disease. Bone. 2009; 45 Suppl 1:S26-S29.

43. Andress D. Nonclassical aspects of differential vitamin D receptor activation: implications for survival in patients with chronic kidney disease. Drugs. 2007;67:1999-2012.

44. Cheng J, Zhang W, Zhang X, Li X, Chen J. Efficacy and safety of paricalcitol therapy for chronic kidney disease: a meta-analysis. Clin J Am Soc Nephrol. 2012;7:391-400.

45. Sprague SM, Llach F, Amdahl M, Taccetta C, Batlle D. Paricalcitol versus calcitriol in the treatment of secondary hyperparathyroidism. Kidney Int. 2003;63:1483-1490

46. Brown JA, Finch J, Slatopolsky E. Differential effects of 19-nor-1,25dihydroxyvitamin D2 and 1,25-dihydroxyvitamin D3 on intestinal calcium and phosphate transport. J Lab Clin Med. 2002;139:279-284.

47. Nakane M, Ma J, Rose AE, et al. Differential effects of vitamin D analogs on calcium transport. J Steroid Biochem Mol Biol. 2007;103:84-89.

48. Sprague SM, Lerma E, McCormmick D, et al. Suppression of parathyroid hormone secretion in hemodialysis patients: comparison of paricalcitol with calcitriol. Am J Kidney Dis. 2001;38:S51-S56.

49. Takahashi F, Finch JL, Denda M, Dusso AS, Brown AJ, Slatopolsky E. A new analog of 1,25-(OH)2D3, 19-NOR-1,25-(OH)2D2, suppresses serum PTH and parathyroid gland growth in uremic rats without elevation of intestinal vitamin D receptor content. Am J Kidney Dis. 1997;30:105-112.

50. Rodriguez M, Martinez-Moreno JM, Rodríguez-Ortiz ME, MuñozCastañeda JR, Almaden Y. Vitamin D and vascular calcification in chronic kidney disease. Kidney Blood Press Res. 2011;34:261-268.

51. Li X, Speer MY, Yang H, Bergen J, Giachelli CM. Vitamin D receptor activators induce an anticalcific paracrine program in macrophages: requirement of osteopontin. Arterioscler Thromb Vasc Biol. 2010;30: 321-326.

52. Sanchez-Niño MD, Bozic M, Córdoba-Lanús E, et al. Beyond proteinuria: VDR activation reduces renal inflammation in experimental diabetic nephropathy. Am J Physiol Renal Physiol. 2012;302:647-657.

53. Resnick LM, Müller FB, Laragh JH. Calcium-regulating hormones in essential hypertension. Relation to plasma renin activity and sodium metabolism. Ann Intern Med. 1986;105:649-654.

54. Freundlich M, Quiroz Y, Zhang Z, et al. Suppression of reninangiotensin gene expression in the kidney by paricalcitol. Kidney Int. 2008;74:1394-1402.

55. Park JW, Bae EH, Kim IJ, et al. Renoprotective effects of paricalcitol on gentamicin-induced kidney injury in rats. Am J Physiol Renal Physiol. 2010;298:301-313.

56. Sochorová K, Budinský V, Rozková D, et al. Paricalcitol (19-nor-1, 25-dihydroxyvitamin D2) and calcitriol (1,25-dihydroxyvitamin D3) exert potent immunomodulatory effects on dendritic cells and inhibit induction of antigen-specific T cells. Clin Immunol. 2009;133:69-77.
57. Ari E, Kedrah AE, Alahdab Y, et al. Antioxidant and renoprotective effects of paricalcitol on experimental contrast-induced nephropathy model. Br J Radiol. 2012;85:1038-1043.

58. Meems LM, Cannon MV, Mahmud H, et al. The vitamin D receptor activator paricalcitol prevents fibrosis and diastolic dysfunction in a murine model of pressure overload. $J$ Steroid Biochem Mol Biol. 2012;132:282-289.

59. Husain K, Ferder L, Mizobuchi M, Finch J, Slatopolsky E. Combination therapy with paricalcitol and enalapril ameliorates cardiac oxidative injury in uremic rats. Am J Nephrol. 2009;29:465-472.

60. Park JW, Cho JW, Joo SY, et al. Paricalcitol prevents cisplatininduced renal injury by suppressing apoptosis and proliferation. Eur $J$ Pharmacol. 2012;683:301-309.

61. Mizobuchi M, Morrissey J, Finch JL, et al. Combination therapy with an angiotensin-converting enzyme inhibitor and a vitamin D analog suppresses the progression of renal insufficiency in uremic rats. $J \mathrm{Am}$ Soc Nephrol. 2007;18:1796-1806.

62. Husain K, Suarez E, Isidro A, Ferder L. Effects of paricalcitol and enalapril on atherosclerotic injury in mouse aortas. Am J Nephrol. 2010;32:296-304.

63. Kong J, Kim GH, Wei M, et al. Therapeutic effects of vitamin D analogs on cardiac hypertrophy in spontaneously hypertensive rats. Am J Pathol. 2010;177:622-631.

64. Mizobuchi M, Nakamura H, Tokumoto M, et al. Myocardial effects of VDR activators in renal failure. J Steroid Biochem Mol Biol. 2010;121: 188-192.

65. Fraga $\mathrm{C}$, Blanco $\mathrm{M}$, Vigo E, et al. Autogenesis of the vitamin D receptor in the rat heart. Histochem Cell Biol. 2002;117:547-550.

66. Wu-Wong JR, Noonan W, Nakane M, et al. Vitamin d receptor activation mitigates the impact of uremia on endothelial function in the 5/6 nephrectomized rats. Int J Endocrinol. Epub February 10, 2010.

67. Mizobuchi M, Finch JL, Martin DR, Slatopolsky E. Differential effects of vitamin $\mathrm{D}$ receptor activators on vascular calcification in uremic rats. Kidney Int. 2007;72:709-715.

68. Cardús A, Panizo S, Parisi E, Fernandez E, Valdivielso JM. Differential effects of vitamin $\mathrm{D}$ analogs on vascular calcification. $J$ Bone Miner Res. 2007;22:860-866.

69. Teng M, Wolf M, Lowrie E, Ofsthun N, Lazarus JM, Thadhani R. Survival of patients undergoing hemodialysis with paricalcitol or calcitriol therapy. Engl J Med. 31, 2003;349:446-456.

70. Tentori F, Hunt WC, Stidley CA, et al. Mortality risk among hemodialysis patients receiving different vitamin D analogs. Kidney Int. 2006;70:1858-1865.

71. Cozzolino M, Brancaccio D, Cannella G, et al. VDRA therapy is associated with improved survival in dialysis patients with serum intact PTH $<=150 \mathrm{pg} / \mathrm{mL}$ : results of the Italian FARO Survey. Nephrol Dial Transplant. 2012;27(9):3588-3594.

72. He W, Kang YS, Dai C, Liu Y. Blockade of Wnt/? - catenin signaling by paricalcitol ameliorates proteinuria and kidney injury. $J$ Am Soc Nephrol. 2011;22:90-103.

73. Aperis G, Paliouras C, Zervos A, Arvanitis A, Alivanis P. The role of paricalcitol on proteinuria. J Ren Care. 2011;37:80-84.

74. Agarwal R, Acharya M, Tian J, et al. Antiproteinuric effect of oral paricalcitol in chronic kidney disease. Kidney Int. 2005;68:2823-2828.

75. de Zeeuw D, Agarwal R, Amdahl M, et al. Selective vitamin D receptor activation with paricalcitol for reduction of albuminuria in patients with type 2 diabetes (VITAL study): a randomised controlled trial. Lancet. 2010;376:1543-1551.

76. Thadhani R, Appelbaum E, Pritchett Y. Vitamin D therapy and cardiac structure and function in patients with chronic kidney disease: the PRIMO randomized controlled trial. JAMA. 2012;307:674-684. 
Clinical Interventions in Aging

Dovepress

\section{Publish your work in this journal}

Clinical Interventions in Aging is an international, peer-reviewed journal focusing on evidence-based reports on the value or lack thereof of treatments intended to prevent or delay the onset of maladaptive correlates of aging in human beings. This journal is indexed on PubMed Central, MedLine, the American Chemical Society's 'Chemical Abstracts

Service' (CAS), Scopus and the Elsevier Bibliographic databases. The manuscript management system is completely online and includes a very quick and fair peer-review system, which is all easy to use. Visit $\mathrm{http}: / /$ www.dovepress.com/testimonials.php to read real quotes from published authors.

Submit your manuscript here: http://www.dovepress.com/clinical-interventions-in-aging-journal 